\title{
Success factors for the commercialisation of Gas-to-Liquids technology
}

\author{
K.E. Meleloe ${ }^{a}$ and D.R. Walwyn ${ }^{b}$ \\ apetroSA (Pty) Ltd \\ bepartment of Engineering and Technology Management, University of Pretoria, \\ Private Bag X20, Hatfield, Pretoria 0028, South Africa \\ *To whom all correspondence should be addressed \\ david.walwyn@up.ac.za
}

\begin{abstract}
Notwithstanding the 2014/15 plunge in crude oil prices, Gas-to-Liquids (GTL) technology has been acclaimed as an important alternative to existing sources of liquid fuels, leading to significant efforts by many oil and gas companies, including Sasol, Shell, Axens, BP, GTL.F1, JOGMEC and Rentech, to develop GTL processes. However, only two companies, namely Sasol and Shell, have been successful with these endeavours. In this research, a mixed methods approach has been used to explore the reasons for this success, including the influence of commercial and technical factors. A framework consisting of five commercialisation success factors was developed and an analytical hierarchy process used to compare and rank the different success factors following interviews with a diverse set of role players in the GTL industry. It is clear that large-scale GTL projects require massive capital investment and carry large techno-economic risks. Moreover, an accurate return on investment is impossible to predict due to uncertainties in technology performance and market factors. As a consequence, project developers and financiers mitigate their risk by securing co-investment from GTL operators. Shell and Sasol dominate the GTL industry not necessarily because their technologies offer higher returns, but because they have jointly invested in GTL projects, an approach which subscribes to a model of technology push with risk sharing. It is recommended that other licensors should pursue the large scale validation of their technology at an existing syngas facility as a strategy to gain entry into the GTL market.
\end{abstract}

\section{Introduction}

During the last three decades, several Gas-to-Liquids (GTL) projects have been developed as attractive alternatives for natural gas owners to monetise their gas and thereby diversify their energy mix (Wood et al., 2012). GTL processes produce a variety of high-quality liquid fuels, including diesel with a high cetane number and low diesel content, and jet fuel (Wood, 2005).

The first wave of GTL developments in Qatar was as a result of the abundant supply of economically-priced stranded gas. The natural gas to oil price differential that has persisted in North America, driven by increased shale gas production, has also sparked renewed interest in developing GTL projects. At low natural gas prices (i.e. <US\$ 4/MMBTU) and high crude oil prices (>US\$ 75/barrel), a good commercial case can be made for GTL technologies (Wood et al., 2012). Although crude oil prices are currently well below their 2014 levels, global interest in GTL is likely to increase for a number of reasons including:
- reduced or depressed gas prices due to increased shale gas discoveries in the United States (US) and hence lower gas prices; although this observation seems to be predominantly applicable to the US, its impact could soon be felt in other parts of the world leading gas owners and fuel industry developers to consider other gas monetization options

- stricter environmental regulations through tighter fuel specifications which make GTL fuel attractive because of its excellent quality (Sajjad et al., 2014)

- the need to develop additional energy resources and diversify fuel supply (Ghaemmaghami, 2001; Rahmin, 2005).

The main conversion process in all the recent GTL project developments is Fischer Tropsch (FT) synthesis, and it dominates both large and small-scale projects targeting middle distillate liquid transportation fuel markets or speciality chemicals such as wax, lubes and paraffinic solvent. There have been numerous FT technology development activities in the last three decades, all of which have been aimed at the monetization of stranded gas resources using GTL processes. A list of FT technology licensors is shown in Table 1. 
Table 1: Overview of the FT synthesis licensors

\begin{tabular}{llll}
\hline Licensors & Reactor Type & Test unit capacity & Location \\
\hline ConocoPhillips & Slurry phase & $400 \mathrm{bpd}$ & Oklahoma, USA \\
ExxonMobil & Slurry phase & $200 \mathrm{bpd}$ & Louisiana, USA \\
Eni/IFP/Axens & Slurry phase & $20 \mathrm{bpd}$ & Sannazzaro, Italy \\
Syntroleum & Slurry phase & $100 \mathrm{bpd}$ & Oklahoma, USA \\
JOGMEC & Slurry phase & $500 \mathrm{bpd}$ & Yufutsu, Japan \\
GTL.F1 & Slurry phase & $1000 \mathrm{bpd}$ & Mossel Bay, RSA \\
BP / Davy & Fixed bed & $300 \mathrm{bpd}$ & Alaska, USA \\
Rentech & Slurry phase & $10 \mathrm{bpd}$ & California, USA \\
Shell & Fixed Bed & $3 \mathrm{bpd}$ & Amsterdam, Netherland \\
Sasol & Slurry phase & $400 \mathrm{bpd}$ & Sasolburg, South Africa \\
\hline
\end{tabular}

Source: Godorr (2011), Steynberg and Dry (2004), Steynberg (2004), Velasco et al. (2010)

All the existing GTL facilities and projects under construction presently use or are designed to use Sasol or Shell technology, despite other licensors having larger technology demonstration units or pilot plants than either Sasol or Shell. It is apparent that the competing FT technology licensors, other than Shell and Sasol, have struggled to enter the GTL markets. In this study, the reasons for this failure, and particularly whether this has been a direct consequence of their commercialisation strategy, have been explored. A mixed methods approach has been followed to identify the key commercialisation success factors, and to determine how influential these factors have been in the success or failure of the various licensors.

\section{Overview of GTL and commercialisation}

\section{GTL technologies}

GTL involves the chemical conversion of natural gas into a synthetic mixture, which can then be upgraded and separated into useful hydrocarbon fractions including liquid transportation fuels. The technology can also be used to convert other abundant natural resources such as coal and biomass to fuels and value added chemicals, these processes being referred to as coal-to-liquid (CTL) and biomass-toliquid (BTL) respectively.

The GTL process was first discovered by the two renowned German professors, Fischer and Tropsch, in the 1920s. Their process, known as the FT process, was used by Germany during World War II and by South Africa from the 1950's, the latter mainly as a consequence of economic sanctions and embargoes. Even today, the leading GTL technology remains the FT process (Bao et al., 2010).

Nevertheless FT is not the only process being used in GTL plants. Other processes include the conversion of gas to high value chemicals and derivatives through commercially proven processes like methanol synthesis. The FT technology can therefore be integrated into facilities where synthesis gas is already available (e.g. methanol plants and gasification of solid carbonaceous feedstock like coke or underground coal gasification) to reduce synthesis gas production investment cost, including associated offsite and utility units. In some of these options, gas composition might have to be adjusted to the required composition for FT synthesis.

The FT-based GTL process consists of three main steps as shown in Figure 1. In the first step, natural gas is reformed to produce synthesis gas (syngas), the latter being a mixture of carbon monoxide $(\mathrm{CO})$ and hydrogen $\left(\mathrm{H}_{2}\right)$. The second step involves FT synthesis, which converts syngas to synthetic products. In the final step, the FT products are upgraded using cracking and hydro-processing units to yield products that meet the required market specifications (Bao et al., 2010).

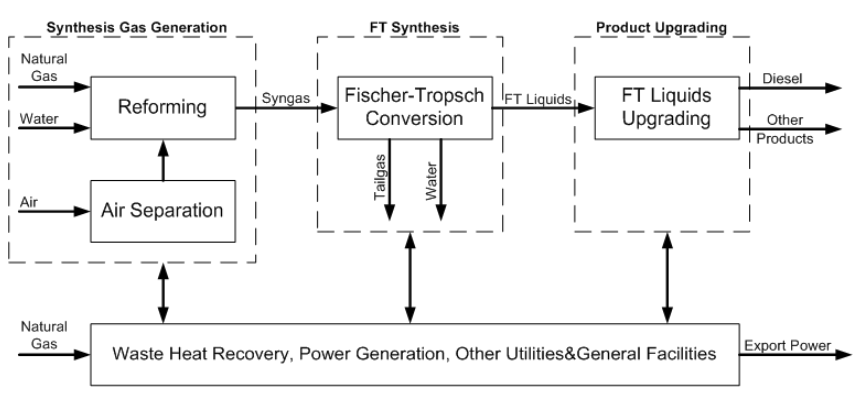

Figure 1: Overview of the GTL process

Source: Adapted from Djakovic (2011)

GTL can address a number of important issues and challenges in the oil and gas industry including the economic use of remote gas, the impact of stricter environmental regulations, especially through tighter fuel specifications, and the overdependence of the industry on crude oil (Keshav and Basu, 2007).

According to Steynberg (2004), natural gas conversion via FT synthesis in a GTL plant integrates almost all kinds of processes found in the chemical and petrochemical industry, including gas processing, gas conversion to syngas, hydrocarbon synthesis, typical refinery operations, integrated utility systems including power generation, manufacture of specialty chemical products and materials handling. Furthermore, even though the three GTL components are well established, individually optimized, and commercially proven, their combined use is not widely applied, and the challenge for project developers and process designers is to 
obtain the most cost effective combination of these three technologies (Vosloo, 2001).

Although the three components and their effective integration are crucial, the FT component is generally the core of FTbased GTL because it enables the conversion of synthesis gas to liquid hydrocarbons. As a result, an understanding of FT is essential for this analysis (Bao et al., 2010).

\section{Fischer Tropsch synthesis}

The conversion of the synthesis gas to liquids takes place in a highly exothermic FT reactor. There are four types of FT reactors in commercial use at present: circulating fluidized bed reactors, fluidized bed reactors, tubular fixed bed reactors, and slurry phase reactors (Pérez Angulo et al., 2005; Sie and Krishna, 1999).

These reactors operate in either a low temperature (LTFT) or a high temperature FT regime (HTFT) regime, where LTFT covers $200^{\circ} \mathrm{C}$ to $240^{\circ} \mathrm{C}$ and HTFT from $300^{\circ} \mathrm{C}$ to $350^{\circ} \mathrm{C}$. Apart from the operating temperature, the main difference between LTFT and HTFT is that in HTFT reactors there is no liquid phase present outside the catalyst particles (Velasco et al., 2010).

According to Sajjad et al. (2014), the most common metals used as FT catalysts are the group VIII metals iron, cobalt, nickel and ruthenium, all of which have sufficiently high activities for the hydrogenation of $\mathrm{CO}$ to warrant their application. The two most preferred and highly used catalysts, because of cost and selectivity, are cobalt and iron. In South Africa, all FT plants use iron catalysts, while the Shell plant in Malaysia and the Oryx plant in Qatar use cobalt (Dry, 2008). All the recent projects by Shell and Sasol use cobalt catalysts.

According to Steynberg (2004) and Dry (2008), cobalt catalysts are more active than iron-based catalysts and have a very good selectivity to long chain paraffins. As a result, all diesel-producing plants use cobalt in LTFT reactors, while iron catalysts operating in HTFT reactors are preferred for the production of gasoline and linear 1-alkenes (Remans et al., 2008; Steynberg et al., 2004).

\section{Commercial FT plants}

The initial FT plants were constructed in South Africa by Sasol, with the first facility being commissioned at Sasolburg in 1956 and the second at Secunda in 1980. These plants produce liquid fuel mostly from coal-derived synthesis gas. The total Sasol production capacity of the South African (Sasolburg and Secunda) FT-based plants is around 165,000 bpd (Velasco et al., 2010).
The first GTL plants outside South Africa were predominantly in Qatar and Nigeria. Sasol built its largest low temperature FT technology plant in Qatar (Oryx GTL plant) with a capacity of $34,000 \mathrm{bpd}$, followed by the Escravos GTL plant in Nigeria (same capacity as Oryx GTL), and is now also expanding its Sasolburg production using the same technology. Oryx and Escravos GTL were commissioned in 2006 and 2014, and cost \$1.4 billion and $\$ 10$ billion respectively.

The FT technology used at the Oryx plant was the first cobalt based LTFT commercial unit constructed by Sasol. The plant suffered a number of initial challenges, which was described as "a source of disappointment felt through-out the entire GTL industry" (Forbes, 2012). Sasol, however, had the capacity and interest to resolve the problems at Oryx and the plant is now operating as intended, even above design capacity. The same technology was used at Escravos GTL.

Shell's investments were focussed on the Bintulu plant in Malaysia (the latter being commissioned in 1993) and the Pearl project in Qatar, which was commissioned in 2011. The latter cost $\$ 19$ billion dollars to build (the biggest ever investment in the GTL sector), had 52000 workers onsite at the peak of construction and today produces $260000 \mathrm{bpd}$ of finished products, of which $140000 \mathrm{bpd}$ derives from GTL (Forbes, 2012). It was the first GTL project to be started after a challenging commissioning of Oryx GTL and as a result the entire industry eagerly awaited Shell's announcement that the project was working at full design capacity. Less than five years after the Final Investment Decision (FID), the Pearl project delivered its first cargo of on specification product and later celebrated a successful ramp-up to design capacity (Forbes, 2012). Shell's state-of-the-art proprietary GTL process, the Shell Middle Distillate Synthesis (SMDS), is currently used in Shell's Bintulu plant in Malaysia and the Pearl plant in Qatar.

With the exception of the PetroSA GTL plant in Mossel Bay, all GTL facilities are operated by Sasol and Shell and to date, all licensed FT technologies used in commercial GTL facilities have been provided by Sasol and Shell, as shown in Table 2.

The second wave of GTL project development is now on the horizon and Sasol is involved in two additional GTL plants: a 96000 bpd GTL plant in Louisiana (to be built in two phases of $48000 \mathrm{bpd}$ ) and a $38000 \mathrm{bpd}$ plant in Uzbekistan (Djakovic, 2011). Both these projects are expected to announce FID in the near future. Sasol has a $44.5 \%$ share in the Uzbekistan project (Djakovic, 2011) but is yet to announce their shareholding in the Louisiana project. In addition, both Sasol and Shell have each announced a joint pre-feasibility study for a large scale GTL plant in Mozambique (Creamer, 2014). 
Table 2: Current FT-based integrated GTL plants

\begin{tabular}{|c|c|c|c|c|c|}
\hline Technology & Company & $\begin{array}{c}\text { Capacity } \\
\text { (bpd) }\end{array}$ & Catalyst & $\begin{array}{l}\text { Operation } \\
\text { mode }\end{array}$ & Reactor type \\
\hline Shell SMDS process & Shell, Bintulu, Malaysia & 14,700 & $\mathrm{Co}-\mathrm{SiO}_{2}$ & LTFT & Fixed bed \\
\hline Shell SMDS process & Pearl GTL, Qatar & 140,000 & $\mathrm{Co}-\mathrm{SiO}_{2}$ & LTFT & Fixed bed \\
\hline Sasol Slurry bed process & Sasol, Sasolburg & 2,500 & $\mathrm{Fe}$ & LTFT & Slurry \\
\hline Sasol Slurry bed process & Oryx GTL, Qatar & 34,000 & $\mathrm{Co}-\mathrm{Al}_{2} \mathrm{O}_{3}$ & LTFT & Slurry \\
\hline Sasol Slurry bed process & Escravos GTL & 34,000 & $\mathrm{Co}-\mathrm{Al}_{2} \mathrm{O}_{3}$ & LTFT & Slurry \\
\hline Sasol Advanced Synthol & Sasol, Secunda, RSA & 165,000 & $\mathrm{Fe}$ (fused) & HTFT & Fixed fluidized \\
\hline
\end{tabular}

Source: adapted from Sajjad et al. (2014), Velasco et al. (2010) and Keshav and Basu (2007)

\section{Markets for GTL products}

Crude oil price hikes, energy security concerns and environmental drivers have turned the focus of the international fuel market to alternative fuels. GTL diesel is often referred to as a "clean fuel" alternative to diesel due its inherent ability to reduce engine exhaust emissions even with blends of diesel and bio-diesel. The environmental advantages of GTL diesel include its low NOx and sulphur content, coupled with lower aromatics and particulate matter generation upon combustion (Sajjad et al., 2014).

Furthermore its higher cetane number (70 to 80) permits higher engine performance. In a detailed study to illustrate the feasibility of GTL diesel in the context of comparative fuel properties and other car performance measurements, Sajjad et al. (2014) have shown that engine performance and emissions are superior to conventional diesel and bio-diesels, and with the exception of a lower density, GTL diesel has excellent properties compared to biodiesel and conventional diesel.

Global diesel demand is growing faster than other refinery products, putting pressure on refiners to adjust their processes (Cherrillo et al., 2003; Wood et al., 2012). This growth in diesel demand is predicted to continue, as shown in Figure 2, and will make LTFT-based GTL plants even more competitive due to their high diesel selectivity. According to Sajjad et al. (2014), prime GTL products include synthetic diesel, kerosene and naphtha. Furthermore, altering FT reactor operating conditions and catalysts can yield high value components like high quality solvents, waxes and paraffins.

The emergence of large scale GTL plants in recent years indicates an increasing demand for GTL products. Furthermore their superior properties suggest that these products should command prices at (or above) petroleumderived liquid fuels. Nevertheless, crude oil price will remain a key factor for GTL economics because GTL products compete directly with those produced from crude oil (Wood et al., 2012). The future of GTL is therefore heavily dependent on the fluctuations in the global oil market.

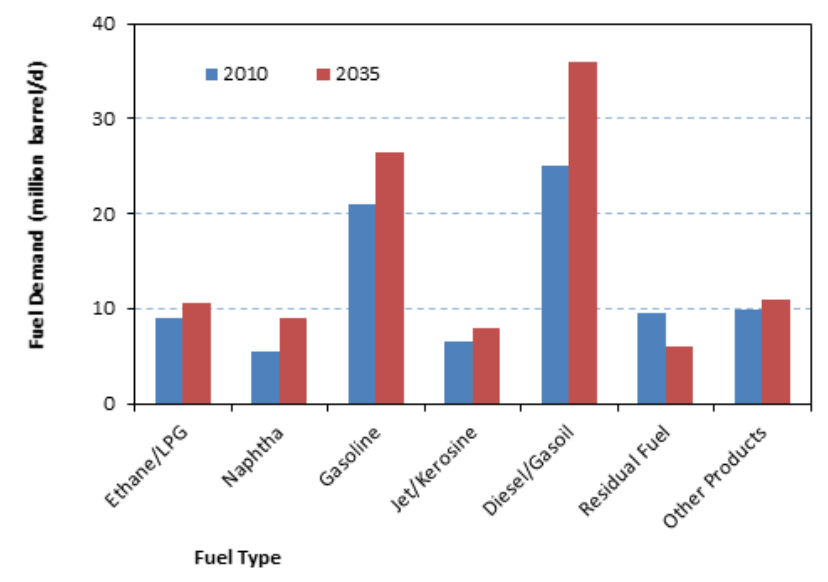

Figure 2: Projects of global fuel product demand by OPEC

Source: OPEC (2011)

\section{Strategic options for GTL technology commercialisation}

Despite the different theories and models for product development, commercialisation is always coupled with uncertainty. Important input variables such as market size, technology reliability and performance, competitor behaviour and economic data are continuously changing and difficult to predict. In all technology development initiatives, there are several paths for a given technology to reach a particular market and the choice of the most appropriate path depends partly on the desired risk mitigation or management strategy for a particular commercialisation opportunity (AmadiEchendu and Rasetlola, 2011). Such strategies should also align both technology-push and market-pull factors.

In the case of GTL, a technology developer could minimise investment risk by only licensing the technology with limited liabilities or could take on more risk and increased time to market by investing in a first of a kind plant using their technology. Either strategy should form part of an overall risk management plan and will depend on the organisation's core business at the time when the technology is launched. Historically the two key issues for the commercialisation of GTL technology have been cost and the reliability of the 
technology (Venkataraman et al., 1998). A medium to large scale $(50,000$ to 150,000 bpd) GTL plant is high cost $(>\$ 5$ billion) and using a commercially unproven technology for such a large investment has a high associated risk. Nevertheless, as has been described, two companies have succeeded in this task. In order to understand the reasons for their success, it is important to initially define the various components of technology commercialisation and hence develop an analytical framework for the study.

The GTL commercialisation framework is based on the important components of risk management, cash flow management/revenue model, and licensing strategy. Consideration of these components has led to the identification of the five GTL commercialisation success factors as shown in Figure 3.

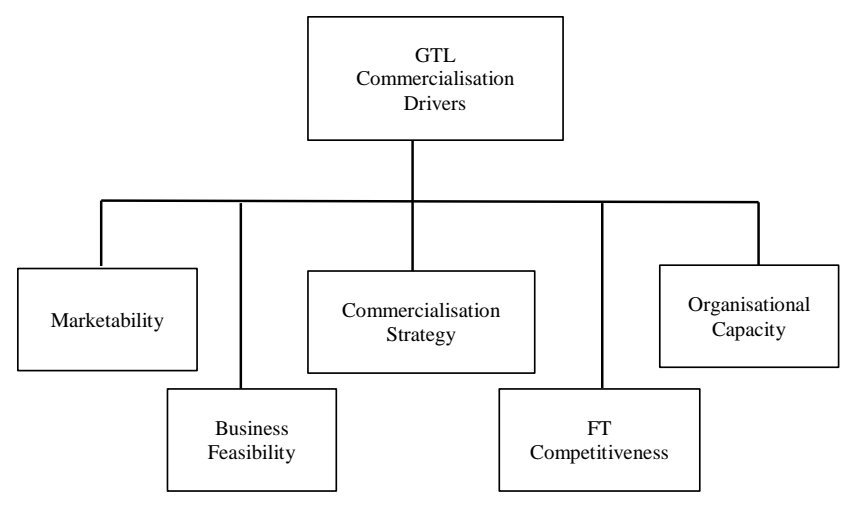

Figure 3: Relevant GTL technology commercialisation drivers (or success factors)

\section{Marketability}

In this analysis, marketability addresses the external factors that impact on the profitability of the GTL project, including the potential market size, the level of technology competition and the evolving needs of the organisation's customer base. Global growth in the demand for clean diesel fuel and diversification of the energy mix (by converting LNG into fuels), thereby also reducing dependency on crude derived products, is making GTL developments more attractive. The increasing needs for clean fuels and a reduced carbon footprint, especially through associated or stranded gas flaring, is also favourable for GTL. The alternative and competitive monetisation of LNG through other commercially proven technologies to high value products remains a major competitor against FT-based GTL on the same feedstock. In summary, market dynamics are influenced by the size and potential growth of the finished products, customer needs for cleaner products and reduced impact on the environment, and the availability of alternative technologies that use the same feedstock as FT-based GTL.

\section{Business feasibility}

There are a number of factors that affect the commercial success of a new product or service and its ability to generate payback, as listed below (Andrew et al., 2013):

- Prelaunch Investment: The size and timing of the prelaunch investment, which indicates as the "depth" of the curve beneath the cash "breakeven" line, is crucial. A large start-up investment may enable a company to develop assets and capabilities that could result in a substantial cash payback, but does not guarantee product launch and may only serve to increase project risk. .

- Speed or Time-to-Market: The commercialisation model proposed by Andrew et al. (2013) identifies speed (timeto-market) and scale (time-to-volume) as important factors for successful technology commercialisation. Increasing the technology launch speed and reducing time to market can increase payback by enabling a company to capture a larger market share at a higher average selling price and by starting the cash flow quickly. An overly aggressive time-to-market may disproportionately increase development costs, reduce the quality of the innovation or have a negative impact on the indirect benefits. In the case of GTL commercialisation, speed is often linked to a window of opportunity to sell a license in a GTL opportunity.

- Time-to-Volume: Time-to-volume is the time from launch to the point at which a new product achieves production volume on the planned scale. A company can control its strategy to supply the product or technology, but it cannot dictate market acceptance. The time-tovolume part of the cash curve should be as short and steep as possible, thereby enabling the innovation to reach the required volume quickly, after which it will begin generating cash profits.

- Support for Ongoing Development: To maximize the return on investment in a new product or service and increase the competitiveness of the technology, a company must invest to support continuous improvement and marketing activities, including both technology and product enhancement initiatives. In the GTL sphere, continuous improvement is crucial to ensure that the technology providers remain competitive and maintain their intellectual property position. Not only does it enable the licensor and/or licensee to operate and sell the product, but it is a possible source of cash if there is an infringement and even a strategy to eliminate competition in certain critical markets.

In addition to the above points, favourable project economics also depend on global raw material and product prices, current and projected product demand and supply, construction and equipment costs, availability of proven technologies and attractive fiscal conditions. A positive economic climate is essential for attractive project economics, whilst reliable and efficient technologies are required to achieve high product qualities and throughputs. 


\section{Commercialisation strategy}

A number of partnership strategies are possible including joint ventures (all parties invest in the project to a significant extent), and licensing of the core technologies (the licensor usually does not invest in this case).

\section{FT competitiveness}

The competitiveness of the FT technology from the different licensors depends on several factors including the level of assets at risk, the potential improvement in the competing technologies, the extent of operating experience of the licensor, the size at which the technology has been demonstrated and the patent security (restriction on competitors to use the key aspects of the licensed technology).

\section{Organisational capacity}

Organisational capacity refers principally to the capacity of the licensor to support the required technology development effort, including R\&D capabilities, management, support for continuous development and expertise in new product development. The latter is usually high cost and needs to be minimised whilst not compromising the final technology. Controlling the commercialisation cost (at a low level), decreasing time to market, and deploying the technology only in a joint venture can yield good returns in a market where product needs and prices remain at expected levels for short periods only.

\section{Methodology}

As already stated, the aim of the research was to prioritise the drivers for the commercialisation of GTL technology by examining their relative importance. A range of stakeholder groups were surveyed and asked to assess the drivers, and provide verbal feedback on the commercialisation framework, an approach which used a combination of research methods, known as mixed method research, as it involved collecting both qualitative and quantitative data; it also provided a more complete understanding of the research problem than either of the approaches alone (Creswell, 2013).

Although most of the operational GTL facilities use only Shell and Sasol FT technology, the recent GTL project developments have involved a number of industry role players. The researcher identified and then selected a representative sample from the following groups to fulfil the criteria of a representative study population (Kumar, 2014):

- GTL Operators: This included participants with operational experience and currently involved in capital projects development.

- GTL Business Developers: Project and business developers involved in the evaluation of GTL opportunities for their employers or a new business venture. This group also included participants who have been involved in the evaluation of large projects for their organisations.

- GTL Execution Experts: Representatives from engineering and construction companies that have participated in the design and construction of large projects. This group also included subject matter experts in GTL.

- Technology Licensors: This included GTL process technology developers for FT, syngas and upgrading technology, and catalyst suppliers for these technologies.

This sampling approach can be broadly defined as stratified purposive sampling.

\section{Design of the survey}

Using the framework defined in the conceptual model, a survey questionnaire was designed and sent by email to the selected sample frame for their response on the importance of the identified GTL commercialisation drivers. This format was adopted as the data collection instrument because of the ease with which the different participants could be reached. Only closed-ended questions were asked and a brief overview of the project was provided with the questionnaire. The latter was designed to collect a subjective view of the respondents on the GTL commercialisation drivers.

The respondents were also asked to evaluate the relative significance of the identified drivers using an 'analytical hierarchy model' approach. The level of importance for each of the commercialisation drivers was then determined based on their respective scores in the model.

Response rates

The final sample comprised of 71 participants from 32 different organisations involved with GTL and GTL commercialisation. A summary of the response rates from the various sample sub-populations responses is provided in Table 3.

Table 3: Overview of the survey respondents

\begin{tabular}{lccc}
\hline Stakeholder & Sample & $\begin{array}{c}\text { Companies } \\
\text { represented }\end{array}$ & $\begin{array}{c}\text { Non } \\
\text { Responses }\end{array}$ \\
\hline $\begin{array}{l}\text { GTL Operators } \\
\text { GTL Business }\end{array}$ & 16 & 7 & 7 \\
$\begin{array}{l}\text { Developers } \\
\text { GTL Execution }\end{array}$ & 15 & 8 & 6 \\
$\begin{array}{l}\text { Experts } \\
\text { Technology }\end{array}$ & 21 & 11 & 6 \\
$\begin{array}{l}\text { Licensors } \\
\text { Total }\end{array}$ & 71 & & 11 \\
\hline
\end{tabular}

\section{Results}

A summary of the responses from the various subpopulations is now presented:

GTL Operators and Business Developers: Based on the survey, business feasibility and FT competitiveness are the most important drivers for these two groups, with their focus 
being on the 'realisation' side of commercialisation (i.e. the time period between commissioning and end of project life cycle) (Andrew et al., 2013). The start-up of the Shell and Sasol plants in Qatar are examples of smooth and challenging ramp-ups to capacity experienced by both companies respectively. GTL developments, like most projects, often have a limited window of opportunity during which they can realise profitable returns. A commercially proven technology and the right business conditions are the two most important drivers required to seize the most of such opportunities.

Technology Licensors: Although technology licensors acknowledge the importance of business feasibility in the attractiveness of GTL projects, they regard the partnership strategy and the organisational capacity to support development and commercialisation efforts as the most important drivers. Both factors are considered essential to the successful transfer of technology from development to commercial operations; excessive delays and hence cost quickly increase the commercial risk and reduce any potential returns on their investment in technology development.

In commercialisation, speed to launch/market is critical. Technology licensors therefore highlight the importance of delivery on the 'commercialisation' side of the project (Andrew et al., 2013). Taking too long to reach the launch point could result in huge development costs and possibly total technology failure due to the development of emerging technologies (i.e. disruptive technologies targeting niche markets) or further developments by companies with proven commercial technologies. An iterative and interactive path to commercialisation in which the licensors can continuously innovate to improve existing operations or upgrade their present technology packages is important, and needs to be supported by the required technical capacity and expertise.

Medium to large scale GTL project developments are expensive, and proven technology and operational capacity are important in securing finance for such projects. The risks associated with such investments are best expressed by the following licensor respondents' quotes:

Respondent 2: "Today business is characterized by a low risk appetite. High profits shall be obtained with ideally no risk. Projects are initially screened for their profitability only. Complexity and importance of a proper commercialisation strategy is often underestimated and leads to inaccurate predictions of the project economics. Many of the current GTL projects suffer from failing to set up a realistic commercialisation strategy".

Respondent 4: “.... GTL opportunities with a sufficiently low-cost feedstock often only open briefly and speed (time to launch) is critical in responding or the commercial plant may not see the benefit from the best economic (return) period. The significant capital and risk associated with GTL facilities naturally will direct attention to relative competitiveness of the technology. Investors cannot afford to make a mistake!"

\begin{abstract}
Respondent 5: "F-T is quite new in commercial application. Typical characters of projects and technology are high risk, huge investment. Therefore all activities with respect to projects and development need a long term strongly committed strategy. From my view: an additional strong impact is the sustainable commitment to investments in development of project/technology and therefore a strong organisational capacity is mandatory".
\end{abstract}

Although Rudgley (2014) is correct regarding the exceptional historical circumstances that were suitable for large scale GTL developments, especially low gas prices that were prevalent during the construction of Oryx, Escravos and Pearl, both Sasol and Shell adopted a crucial risk mitigation strategy that made it possible for the development of these projects. Sasol and Shell did not only offer the technology with limited liability for the technology licensor, but they were investors in these facilities. Both Sasol and Shell are 49\% shareholders in the Oryx and Pearl GTL plants respectively, with the remaining majority shareholding belonging to Qatar Petroleum. Sasol has a reduced shareholding of $10 \%$ in Escravos GTL (Chevron and Nigerian Petroleum company has $75 \%$ and $15 \%$ shareholding respectively) as a result of increased construction costs and project delays (Atuanya, 2014).

The successful commercialisation of other FT technologies remains critical in ensuring proven commercial technology other than Sasol and Shell. To date, most of these organisations have opted for FT technology commercialisation through licensing, but the current dominance by both Shell and Sasol proves that this strategy is unlikely to succeed. The investment cost for a medium to large size GTL plant is of high risk; as a result a licensing strategy that limits the liability of the licensor leaves much of the commercialisation risk with the project developer or operating company, especially if the performance of the technology is not reaching its expected yields and capacities.

\section{Discussion}

\section{GTL economics}

It is apparent that GTL plants are highly profitable as long as they encounter favourable business conditions (Downstream Business, 2014), the latter including cheap, abundant natural gas and a tight, costly oil (Forbes, 2012). Such conditions existed in 2012/3, during which period Shell reported that Pearl GTL was the main driver behind its $35 \%$ increase in cash flow and Sasol reported a revenue rise of $24 \%$ year-onyear for the Oryx GTL plant in Qatar (Peckham, 2014).

Although such conditions existed in 2013/4, the sudden drop in international oil prices has reversed the investment climate and many of the GTL projects are now on hold. Indeed the changing economic context has clarified the breakeven point for GTL, with Sasol reporting that it requires a ratio between the oil price (expressed as $\$ /$ barrel) and the gas price (expressed as $\$ /$ million British thermal units) of at least 16 for a GTL project to succeed. This ratio spiked in early 2012, 
reaching as high as 30, but has subsequently fallen to 17 (see Figure 4). As a result, Sasol has announced the postponement of a \$11 billion GTL project on Louisiana's Gulf Coast, citing the plunge in oil price as the main factor responsible for their decision (McGroarty and Sider, 2015).

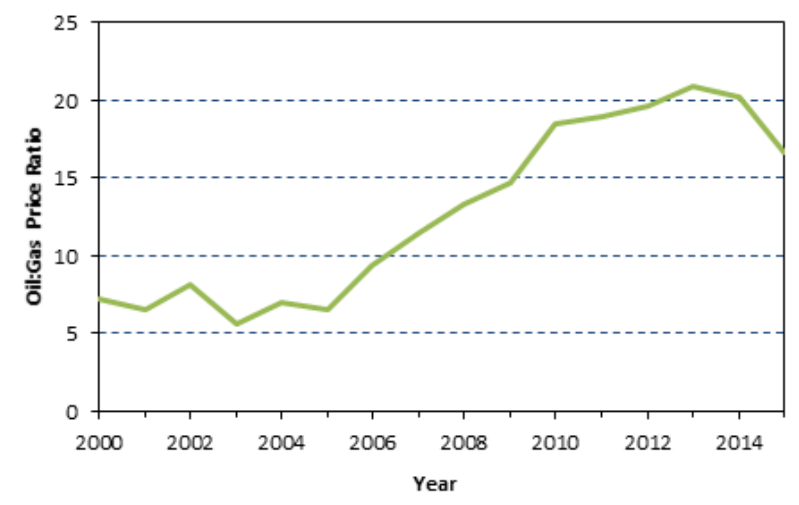

Figure 4: Average ratios of WTI crude oil (\$/barrel) to natural gas prices (\$/million Btu)

Source: Salehi et al. (2013)

Despite the recent successful commercialisation of Shell and Sasol technologies at a large scale, growth will be constrained by the development and availability of proven technology that work reliably and efficiently (Forbes, 2012). Project developers require exceptional economic circumstances in order to access viable projects economics (Rudgley, 2014) while simultaneously assessing the impact of disruptive technologies to large scale GTL developments (e.g. modular GTL technology, LNG to market or power, and gas to gasoline or chemical via methanol).

\section{Implications for GTL commercialisation}

GTL plants are capital intensive, highly integrated, and generally have a lifetime of more than 30 years. The commercialisation rewards for a successful launch are equivalent to the risk for a failed launch, especially if an organisation (or project developer) does not have the capacity and funds to "engineer-out" the problems. The task of raising billions of dollars in the debt markets for a FT based GTL plant is not a trivial effort. The recent GTL developments, predominately in Qatar and North America, enjoyed a fair share of low gas prices, government drive for diversified energy mix, and environmental pressures for clean fuel and less flared gas, but have unfortunately not enjoyed similar financial support as early developments. The enormous GTL development costs and technology commercialisation risks were shared by both the technology and project developers. This is one way of introducing a new technology into the market which is in line with the linear market push commercialisation theory. This is similar to what Respondent 6 in the licensor group referred to as "skin in the game" in which a technology licensor or solution provider is part of the project development joint venture company and contributes equity to move the project forward.
The importance of time-to-market (i.e. speed) as well as growth and continuous improvement, as proposed by Andrew et al. (2013) should be used to inform commercialisation strategy for capital intensive and integrated processes like FT based GTL plants. Based on these two important commercialisation concepts, the following is recommended for technology licensors (other than Sasol and Shell):

- Abandon a technology licensing approach and become an investor in the commercialisation of a GTL project using their FT technology. This option could require significant investment by the other technology companies, most of which are not international oil companies with attractive balance sheets and therefore, such investments will be equally risky for them or difficult to formulate into attractive proposition for lenders to fund.

- $\quad$ Build, operate and maintain a FT process at a suitable non-FT based GTL facility or other facilities that will require minimum capital expenditure to provide the feedstock required for the FT unit. The advantage with this option is that it will significantly reduce the cost of commercial plant development as the focus is only on the FT unit and not all process units required for a typical GTL facility, including utilities and gas conditioning. The overall process could also be configured so that the feed gas is diverted from the FT unit to the existing plant in case of start-up challenges, thereby reducing downtime and commissioning costs. A suitable productservice integration contract with customers and/or companies seeking to monetize gas resources could also be established to compensate the FT technology licensor.

Commercialisation is an art of risk management and the risk management approach will always be different during idea generation and development, compared to that of product launch. Although most commercialisation models follow a sequential approach of product development, commercialisation of GTL technologies requires concurrent thinking and should be done with speed because the window of GTL opportunities has a time span.

\section{Conclusions}

Project developers and operating companies will generally seek to minimise project risk and maximise profitability through the use of proven technology within favourable economic conditions. In the event that proven technology is not available, licensees will consider other mitigating factors such as the extent of demonstration facilities, support for technology commissioning, affiliation with operating companies, intellectual property position and projected technology performance. Technology licensors, on the other hand, look to mitigate technology-related risk and attract potential licensors by adopting well-defined commercialisation strategies.

In the case of GTL, it is apparent that the nature of these strategies has been the determining factor for successful licensing. For instance, a number of FT technology 
developers including GTL.F1, Axens and BP, have demonstrated their technology and declared it ready for commercialisation, but have not yet concluded their first licenses. Shell and Sasol, on the other hand dominate the commercial GTL plants, having adopted a strategy of coinvestment rather than solely licensing agreements. These companies have used their technology as an enabler for their investment in GTL facilities, offering not only their technology to project developers on a license agreement basis, but also acting as a co-investor. The commercialisation risk is, therefore, not passed on to the developers by the licensor, but it is shared with the licensor. This model has been extremely successful in enabling Shell and Sasol to be the world leaders in synthetic fuels production from gas and enables these companies to drive their world GTL ambitions with a higher level of confidence.

It is recommended that other technology licensors consider a "technology push" proposition in which they build, operate and maintain an FT unit at a suitable non-FT based GTL facility or a site that requires minimum capital expenditure to provide the feedstock required for the FT unit. The advantage of this approach is that it significantly reduces the cost of the development since the upstream plant is already established and only the FT unit needs to be constructed. A suitable product-service integration contract could be set up to compensate the FT technology licensor. Product customers and/or companies seeking to monetize gas could also invest in such a project.

\section{References}

Amadi-Echendu, J. \& Rasetlola, R. 2011. Technology commercialization factors, frameworks and models. Technology Management Conference, IEEE International. Institute of Electrical and Electronics Engineers, 144-148.

Andrew, J. P., Sirkin, H. L. \& Butman, J. 2013. Payback: Reaping the rewards of innovation, Boston: Harvard Business Press.

Atuanya, P. 2014. \$10bn Chevron Escravos GTL produces first liquids. [online] URL: http://businessdayonline.com/2014/08/10bnchevron-escravos-gtl-produces-first-liquids/\#.VOLfGCyVGh0.

Bao, B., El-Halwagi, M. M. \& Elbashir, N. O. 2010. 'Simulation, integration, and economic analysis of gas-to-liquid processes', Fuel Processing Technology, 91(7): 703-713.

Cherrillo, R.A., Clark, R.H. \& Virrels, I.G. 2003. Shell gas to liquids in the context of a future fuel strategy - technical marketing aspects. 9th Diesel Engine Emissions Reduction Workshop, Newport RI.

Creamer, T. 2014. Potential gas-to-liquids string added to exciting Mozambique energy bow. [online] URL: http://www.engineeringnews.co.za/article/potential-gas-to-liquidsstring-added-to-exciting-mozambique-energy-bow-2014-07-03.

Creswell, J.W. 2013. Research design: Qualitative, quantitative, and mixed methods approaches, London: SAGE Publications.

Djakovic, D. 2011. Gas to liquids - an ideal gas monetisation option. 20th World Petroleum Congress, Doha, Qatar.

Downstream business. 2014. Shell touts 'pearl' GTL plant as 'main driver' behind surging cash flow. [online] URL:
http://www.downstreambusiness.com/item/Shell-Touts-Pearl-GTLPlant-Main-Driver-Surging-Cash-Flow_n70541.

Dry, M.E. 2008. The Fischer-Tropsch (FT) synthesis processes. In: Ertl, G. \& Knözinger, H. (Eds.) Handbook of Heterogeneous Catalysis. Munich: Wiley-VCH.

Forbes, A. 2012. Shell's pearl proves its worth, but it's early days yet for gas-to-liquids. [online] URL: http://www.europeanenergyreview.eu/site/pagina.php?id=3846.

Ghaemmaghami, B. 2001. 'Special report - GTL: progress and prospects: Study yields generic, coastal-based GTL plant', Oil and Gas Journal, 99(11): 64.

Godorr, S. 2011. GTL technology advances. World Petroleum Conference, Doha.

Keshav, T.R. \& Basu, S. 2007. 'Gas-to-liquid technologies: India's perspective', Fuel Processing Technology, 88(5): 493-500.

Kumar, R. 2014. Research methodology: A step-by-step guide for beginners. 4th Edition, Sydney: Sage Publications.

McGroarty, P. \& Sider, A. 2015. Scrapped: Oil prices shelve an \$11 billion Gulf Coast project. [online] URL: http://www.wsj.com/articles/sasol-reviews-investment-plans-forlouisiana-gas-to-liquids-plant-1422446980.

OPEC. 2011. World oil outlook. Organisation of petroleum exporting countries (OPEC) (Vienna).

Peckham, J. 2014. Sasol Offers GTL Updates; Cites 'Strong Operational Performance'. [online] URL: http://www.downstreambusiness.com/item/Sasol-Offers-GTLUpdates-Cites-Strong-Operational-Performance_134580.

Pérez Angulo, J.-C., Cabarcas Simancas, M.-E., Castro, J.A. \& Tobias, Y.-Y. 2005. "Potential of the "gas to liquids-GTL" technology in Colombia', CT\&F-Ciencia, Tecnología y Futuro, 3(1): 7-23.

Rahmin, I.I. 2005. 'Stranded gas, diesel needs push GTL works', Oil and Gas Journal, 103(10): 18.

Remans, T.J., Jenzer, G. \& Hoek, A. 2008. Gas-to-liquids. Handbook of heterogeneous catalysis. Munich: Wiley-VCH.

Rudgley, G. 2014. Gas-to-liquids: No longer a footnote for the upstream industry [online] URL: http://www.rigzone.com/news/oil_gas/a/133364/GastoLiquids_No _Longer_a_Footnote_for_the_Upstream_Industry/?all=HG2.

Sajjad, H., Masjuki, H.H., Varman, M., Kalam, M.A., Arbab, M.I., Imtenan, S. \& Ashrafur Rahman, S.M. 2014. 'Engine combustion, performance and emission characteristics of gas to liquids fuels and its blend with diesel and bio-diesel', Renewable and Sustainable Energy Reviews, 30: 961-986.

Salehi, E., Nel, W. \& Save, S. 2013. 'Viability of GTL for the North American gas market', Hydrocarbon Processing, 92(1): 41-48.

Sie, S. \& Krishna, R. 1999. 'Fundamentals and selection of advanced Fischer-Tropsch reactors', Applied Catalysis A: General, 186(1): $55-70$. 
Steynberg, A. \& Dry, M. 2004. Fischer-Tropsch technology, 1st Edition, Amsterdam: Elsevier.

Steynberg, A., Dry, M., Davis, B. \& Breman, B. 2004. 'FischerTropsch reactors', Studies in Surface Science and Catalysis, 152: 64195.

Steynberg, A.P. 2004. 'Introduction to Fischer-Tropsch synthesis', Studies in Surface Science and Catalysis, 152: 1-63.

Velasco, J.A., Lopez, L., Velásquez, M., Boutonnet, M., Cabrera, S. \& Järås, S. 2010. 'Gas to liquids: A technology for natural gas industrialization in Bolivia', Journal of Natural Gas Science and Engineering, 2(5): 222-228.

Venkataraman, V., Guthrie, H., Avellanet, R. \& Driscoll, D. 1998. 'Overview of US DOE's natural gas-to-liquids R\&D program and commercialization strategy', Studies in Surface Science and Catalysis, 119: 913-918.

Vosloo, A.C. 2001. 'Fischer-Tropsch: A futuristic view', Fuel Processing Technology, 71(1): 149-155.

Wood, D.A. 2005. 'LNG risk profile 1. Where we are: Relationships, contracts evolve along supply chain', Oil and Gas Journal, 103(4): 54-59.

Wood, D.A., Nwaoha, C. \& Towler, B.F. 2012. 'Gas-to-liquids (GTL): A review of an industry offering several routes for monetizing natural gas', Journal of Natural Gas Science and Engineering, 9: 196 - 208. 